\title{
EL SACERDOCIO EN ÉPOCA IBÉRICA
}

\section{THE PRIESTHOOD IN THE IBERIAN SOCIETY}

\author{
por \\ TERESA CHAPA BRUNET* \\ ANTONIO MADRIGAL BELINCHÓN*
}

\begin{abstract}
RESUMEN Este trabajo pretende llamar la atención respecto a un aspecto poco conocido de la religión ibérica: el sacerdocio. Tomando como base la propia estructura de la sociedad, las evidencias materiales y la comparación con otras culturas contemporáneas, se propone la existencia de un clero institucionalizado, ligado al progresivo desarrollo que alcanzan los santuarios y los templos en todo el sur y sureste peninsular a partir del s. V a.C. Se indica asimismo la probable existencia de un sacerdocio femenino a la vez que masculino, y se presentan algunos ejemplos de posibles indicios arqueológicos de personas ligadas al culto.
\end{abstract}

ABSTRACT This paper tries to call attention about a badly known aspect of Iberian religion: Priesthood. Taking account of the Iberian social structure, as well as of the material evidences and the paralellisms with other contemporanean cultures, it is proposed that there was an institutionalised priesthood, linked with the continous development of temples and sanctuaries on the peninsular south and southwest from the Vth. century onwards. It is also stressed that women should have exerted as priestesses as much as men, and some archaeological evidences are proposed to be interpreted as a proof of these people linked with the execution of cult activities.

\section{EL SACERDOCIO EN ÉPOCA IBÉRICA}

Las referencias al sacerdocio son escasas en la bibliografía sobre el mundo ibérico. En el manual de referencia redactado por Arribas (1976) se hacía alusión a la existencia de divinidades representadas por

\footnotetext{
* Departamento de Prehistoria. Universidad Complutense. 28040 Madrid. E-Mail: tchapa@eucmax.sim.ucm.es Este trabajo ha sido realizado dentro del Proyecto DGICYT PB95/0375: El Poblamiento Ibérico en el Sureste Peninsular: una perspectiva espacial. Ministerio de Educación y Cultura. Madrid.
} 
sus símbolos, y de algunos lugares de culto, pero no a la presencia de sacerdotes. Esta situación, en cierta medida perpetuada, se debe a varias causas: en primer lugar, ha existido una corriente de opinión que ha estado en contra de la necesidad del sacerdocio en una sociedad supuestamente simple y centrada en el culto a elementos de la naturaleza (Blázquez 1983: 111). Por otra parte, y al igual que se ha señalado ya para el mundo celtibérico (Marco 1993: 498) se trata de un ámbito relacionado con actividades que dejan escasa huella material, y en las que el componente ideológico tiene un peso destacado. Además, las fuentes antiguas apenas dan cuenta de la presencia de sacerdotes en el mundo ibérico, al contrario de lo que sucede en otras áreas, como la céltica. Finalmente, la iconografía es incierta, no siendo fácil reconocer el sacerdocio a través de atributos externos o de las actitudes de los supuestos personajes de culto

Por el contrario, en el momento presente va siendo una opinión generalizada que tanto entre los iberos como entre los celtíberos debió existir un sacerdocio organizado (entre otros, ver Marco 1993: 499; Aranegui 1994: 307; Nicolini 1969: 64; Prados 1996: 276; Ruano 1987: 179). Sin embargo, no hay ningún trabajo general que establezca de forma sistemática la necesidad de un cuerpo sacerdotal en la sociedad ibérica, al igual que sucedió en otras sociedades contemporáneas No existe tampoco un intento de revisión de la evidencia arqueológica con este fin, de manera que puedan reconocerse personajes ligados al culto mediante el análisis de los restos materiales. Parece necesario, por tanto, iniciar una revisión reflexiva sobre este tema, que resulta de gran importancia en el funcionamiento de un grupo humano. El presente trabajo no pretende ser más que el planteamiento de una serie de interrogantes y la presentación de unas evidencias que abran el camino a la definición y el reconocimiento de un posible clero institucionalizado en este amplio y diverso marco que conocemos como cultura ibérica.

\section{Los modelos externos}

La mayor parte de las sociedades del Mediterráneo, así como las de Europa continental, tienen organizados sus procedimientos rituales de maneras específicas. Como rasgos comunes pueden señalarse:

- La existencia de un grupo de divinidades cuyas acciones afectan directamente a la vida humana.

- La necesidad de que existan unas personas que intercedan, interpreten y favorezcan el designio y las acciones de los dioses en relación a los seres humanos.

— La vinculación, por regla general, de las clases sociales más altas con el ejercicio del sacerdocio, y con los puestos principales en el proceso ritual, aunque su responsabilidad y representatividad variará en cada caso.

Haciendo un rápido repaso al funcionamiento del ritual en el entorno mediterráneo, podemos señalar muy esquemáticamente las siguientes características:

a) Mundo Fenicio-Púnico: La religión fenicia contaba con varias divinidades, cuya importancia se ligaba a las dedicaciones ciudadanas. Cada urbe tenía, por tanto, un panteón específico. Como señala Aubet (1994: 135), los reyes fenicios eran los representantes del dios, oficiando como sumos sacerdotes, y vinculando el templo a la residencia real. La mujer del rey se asociaba así a la divinidad femenina. Existía además un clero extraído de un número reducido de familias que transmitían dentro de su seno el conocimiento necesario (Aubet 1994: 239). Este cuerpo sacerdotal estaba jerarquizado, agrupándose en colegios dirigidos por un jefe de sacerdotes, que gozaba de considerable prestigio (Boumet y Xella 1995:324), participando también en la vida política, como parece deducirse de los sarcófagos cartagineses (Delattre, 1898: 6). En las ceremonias participaba un elevado número de personas, cada una de ellas con un papel bien definido. Dos cargos sacerdotales tenían una relevancia principal: el sacrificador y el resucitador de la divinidad (Ribichini 1988: 116). 
Divinidades femeninas importantes en Fenicia y Cartago fueron Astarté y Tanit, relacionadas entre sí y vinculadas a la fecundidad y al renacimiento tras la muerte (Dictonnaire 1992: 48 y 438). Entre los representantes masculinos pueden citarse a Baal y a Melkart, que con Astarté formaban parte del triduo divino propio de la ciudad de Tiro, y que tuvieron fuerte relevancia en la Península Ibérica a través de las colonias de la costa sur, y especialmente de Cádiz. La iconografía de las divinidades fenicias es limitada, manifestándose a menudo mediante símbolos como el que caracteriza a Tanit.

b) Mundo griego: La religión griega no tenía libros sagrados, ni un credo prefijado, y carecía de cualquier organización eclesiástica centralizada, por lo que cada ciudad tenía una autoridad prácticamente ilimitada en los asuntos religiosos. Excepcionalmente, algunos sacerdocios podían ser hereditarios, desempeñándose dentro de antiguas familias aristocráticas, como los Yámidas en Olimpia (Easterling 1985: 42), los Eumólpidas de Eleusis o los Asclepíades de Kos (Muir 1985: 193). En estos casos, los jóvenes vinculados a los actos religiosos no debían atender servicios de armas (Malkin 1987: 176). Sin embargo, muchos de los sacerdotes ejercían su labor sólo temporalmente, sin que su trabajo requiriera unas cualificaciones especiales. Apenas pueden citarse algunos grupos de expertos, como los exegetai atenienses, que cuidaban de la tradición religiosa, o los hierophantes en los misterios eleusinos (Gould 1985: 7). La gran mayoría de los sacerdotes fueron a menudo oficiales públicos, cuyos deberes incluían responsabilidades en relación con alguna porción de la actividad religiosa de la comunidad (Finley 1985: XV). En otras ocasiones eran elegidos y desempeñaban su cargo solamente durante un cierto tiempo, que podía reducirse a seis meses, como en el caso de Delfos (Finley 1985: XV).

En Grecia, además, adquiere importancia la presencia femenina en el culto, prácticamente la única esfera de carácter público en la que podían participar las mujeres. En general el culto a las diosas era llevado a cabo por sacerdotisas, y la mujer podía alcanzar una altísima consideración social cuando ejercía este ministerio, recibiendo no sólo prerrogativas legales, sino numerosas aportaciones pecuniarias y regalos de lujo. Ellas mismas, sus familias o los fieles podían levantar estatuas que les representaran, y que se situaban a las puertas del templo (Kron 1996: 140-141). Se ha llegado a proponer que las korai áticas de la Acrópolis representaran a las niñas de las mejores familias aristocráticas que servían durante cuatro años como personal de culto en los festivales atenienses más importantes. Sus familiares ofrendarían a la divinidad estas esculturas al final de su periodo de dedicación (Richter 1968: 3). Esta propuesta, sin embargo, no es aceptada de forma generalizada (Spivey 1996: 92). En todo caso, la mujer adquiere un protagonismo notable dentro de la religión griega, como lo tenían también las divinidades femeninas dentro del panteón divino.

c) Mundo etrusco-romano: Las religiones etrusca y romana tienen muchos puntos en común y de nuevo se basan en la supeditación del hombre a la divinidad. Los poderes de los dioses y su acción en el mundo de la vida cotidiana de los individuos, de la familia y de la ciudad deben ser encauzados en favor de los seres humanos. Esto se consigue mediante la correcta práctica de una serie de rituales, por lo que existía una normativa tremendamente estricta respecto a las reglas que debían regir las actividades religiosas. Entre los etruscos, los sacerdotes eran muchos y tenían funciones especializadas. Estaban muy relacionados con las magistraturas públicas, y a menudo se agrupaban en colegios. Algunos de ellos llevaban vestimentas especiales, como los arúspices, representados con un gorro cónico y un manto con los bordes decorados (Pallotino 1975: 150). Sacrificios, adivinaciones y ofrendas eran claves en el proceso ritual, en cuyas ceremonias se celebraban danzas al son de la música, y se recitaban oraciones.

En el mundo romano, la religión tiene como fin proteger a la comunidad, y por lo tanto es un asunto de estado. Los tres principios religiosos básicos son Pietas, Religio y Cultu. En ellos se implica la vigilancia a los designios divinos y la voluntad de hacerles actuar en beneficio de la sociedad. La piedad colectiva e institucional era la que justificaba el éxito de la política romana, y su hegemonía universal. Por tanto, 
la actividad ritual estaba minuciosamente establecida, y las personas relacionadas con ella debían instruirse cuidadosamente en las fórmulas que regían el desarrollo del culto. Así, el Flamen dialis no tiene ninguna libertad de movimientos, y las reglas por las que es elegido y las obligaciones a las que se somete son muy rígidas. Sin embargo, la esfera religiosa y la política estaban estrechamente unidas, y las funciones cultuales no eran en Roma el monopolio de una clase sacerdotal. Los magistrados anuales tomaban los augurios, y tenían la responsabilidad de los sacrificios (Turcan 1988: 3-7). La supervisión de los asuntos religiosos recaía, en todo caso, en los cuatro principales colegios sacerdotales: Pontífices, Augures, Quindecemviri faciundis y Tresviri, que después se convertirá en Septenviri epulones. La pertenencia a estos colegios era muy prestigiosa, en especial la de los dos primeros, ya que eran consultados por el Senado en casi todos los temas controvertidos (Szemler 1972: 21). Cada tipo de sacerdote llevaba atributos específicos, por lo que resulta posible reconocerles por su forma de vestir -el Flamen dialis llevaba un manto de lana teñido en púrpura, y sostenía un bastón y un cuchillo sacrificial o secespita (Turcan 1988: 8)-.

Esta rigurosidad ritual de Etruscos y Latinos hunde sus raíces al menos en las primeras fases de la Edad del Hierro, donde el cuchillo ritual aparece asociado en tumbas tanto masculinas como femeninas de la necrópolis de Osteria dell'Osa, siempre relacionado con ajuares de excepcional riqueza (Bietti Sestieri 1992: 158). En el caso de las tumbas masculinas, la ausencia de armamento parece reafirmar el carácter sacerdotal del difunto (Torelli 1997: 37).

d) Mundo céltico: Las divinidades célticas eran múltiples, y sólo puede pensarse en un reconocimiento generalizado para las más importantes. En ocasiones se ha documentado la existencia de tríadas, tanto femeninas como masculinas. En realidad, todo aquello que forma parte del contexto vital estaba imbuido de sentido religioso, y de una u otra manera revelaba una presencia divina. Bosques, ríos, fuentes y lagos tenían una especial significación, y poseían su propio espíritu. Naturaleza vegetal, animal y humana pertenecían a un mismo universo, y las manifestaciones del arte céltico así lo demuestran. La relación de los grupos humanos con lo sobrenatural se realizaba de muy diversas maneras y, como señala César, el mayor castigo para una persona era privarle de la participación en los actos de carácter ritual. Estos se desarrollaban tanto en un ambiente urbano como en entornos rurales y naturales, que debían ser sacralizados. La propiciación de la acción divina se buscaba a través de los sacrificios, cuyo valor era proporcional al costo que lo sacrificado tenía para cada persona o grupo. Los rituales debían cumplir ciertos requisitos para ser efectivos, y uno de ellos era el de ser conducidos adecuadamente. Para ello existían unos personajes especiales, los druidas, cuya figura es de gran relevancia en esta sociedad. Como sacerdotes, poseían el rango de nobles, y estaban exentos de tributos y servicios de armas, aunque en ocasiones excepcionales podían empunarlas (Green 1993: 452). Conocían la escritura, si bien uno de sus deberes era la memorización de largas leyendas de carácter sacro que no debían ser plasmadas por escrito. En algunas ocasiones se ha hablado de la existencia de sacerdotisas, a partir de enterramientos dentro de recintos sagrados.

\section{El caso ibérico}

Todo lo expuesto anteriormente conduce a la suposición de que en el mundo ibérico existió un sacerdocio, más complejo y autónomo conforme la sociedad progresivamente desarrolla fórmulas también complejas de organización. Sin embargo, existen numerosas dudas acerca de la configuración de este posible clero, de su extracción social, de su papel en la sociedad o de cómo se desarrollarían sus actividades. En todo caso, podemos extraer algunas deducciones de la propia estructura de la sociedad y de los restos arqueológicos relacionados con el culto que han recibido una desigual atención por parte de los especialistas. 
2.1. Los precedentes de la etapa orientalizante: Son muchas las referencias a la práctica del culto en la etapa orientalizante, siempre dentro de una fuerte influencia fenicia. Por ello resulta forzoso ser muy selectivos en la alusión a este fenómeno, limitándonos a dar una mera referencia a algunos puntos de interés que pueden ser representativos de los cambios asumidos en esta fase. Dentro de un contexto funerario, las tumbas principescas de la necrópolis de La Joya incluyen en sus ajuares cuchillos de filo curvo, que pudieran estar relacionados con el acto sacrifial (Garrido y Orta 1978: t. 17 y 19). Lo mismo sucede en otras necrópolis de esta etapa, diseminadas por diversos territorios (enumeradas en Quesada 1997/1: 165). El resto del ajuar, con timiaterios, jarros o braseros, también está muy sesgado hacia actividades de tipo religioso, como la libación. Es de suponer, por tanto, que los portadores de estos cuchillos y del resto de las piezas, tuvieran connotaciones rituales, aunque desconocemos si ello comportaba un rango sacerdotal diferenciado de otro tipo de autoridad. Posiblemente ambos elementos irían unidos, ya que la autoridad política y religiosa debían estar asociadas. Por otra parte, esta dualidad se reproduciría en ciertos miembros de las familias principales, que parecen asimilar connotaciones rituales mediante la práctica del sacrificio.

A pesar de la acumulación de actividades religiosas en los palacios, el entorno fenicio del sur peninsular nos demuestra que los templos tuvieron también importancia por sí mismos. Precisamente uno de los más conocidos de todo el Mediterráneo se encontraba en Cádiz, y estaba dedicado a Melkart, refiriéndose las fuentes a la presencia de sacerdotes. Últimamente la investigación está además reconociendo como lugares sacros algunos recintos que habían sido interpretados de maneras diversas. Es el caso del conjunto de El Carambolo, para el que se propone una función religiosa (Belén y Escacena e.p.). Debemos suponer, por tanto, que además de la existencia de una élite con fuerte acumulación de poder político y religioso, éste último tenía también una cierta autonomía, y que los templos y centros de culto debieron contar con un personal especializado, aún hoy difícil de reconocer arqueológicamente, pero cuyos indicios habrá que ir perfilando poco a poco. Las pocas fuentes escritas con las que cuenta el fenómeno religioso, y en concreto el del sacerdocio en época prerromana, se refieren precisamente al Templo de Melkart, en Cádiz, que tanta importancia tuvo en la gestión de la colonización fenicia y en el mantenimiento de su actividad ideológica y económica. El conocido pasaje de Silio Itálico (III, 1) afirma la credibilidad de las profecías de este lugar, y proporciona una descripción de sus oficiantes, que portaban túnicas sueltas de lino bordeadas de púrpura y llevaban la cabeza rasurada y ceñida con una cinta.

La presencia fenicia y su fuerte incidencia en el territorio peninsular provocaría cambios en las estructuras indígenas, desarrollándose lo que Almagro-Gorbea (1996: 41) define como "monarquías sacras". En ellas, a semejanza de los sistemas religiosos orientales, existiría una concepción teocrática del poder, que radicaría en la divinidad, administrado a través de su sumo sacerdote, el rey, cuyo carácter sacro fundamentaba su poder político. Templo y palacio se confunden, ya que la morada divina es también la residencia regia (Almagro-Gorbea 1996: 74). Manifestaciones de este poder concentrado de la esfera política, económica y religiosa, serían palacios como el de Cancho Roano (Celestino 1995), a pesar de su cronología tardía, o probablemente asentamientos como el de La Quéjola, donde los elementos de culto van acompañados de una notable práctica de acumulación (Blánquez 1996). Otro caso propuesto es el de la torre funeraria de Pozo Moro, con iconografía de inspiración oriental, y en la que existe además una referencia a un acto sacrificial (Almagro-Gorbea 1978: 274). En la Alta Andalucía, la capacidad para construir grandes recintos fortificados (Cunliffe et al 1993: 523) y gestionar políticas a nivel territorial (Ruiz y Molinos 1993) pueden ser otras muestras de ese poder concentrado, que en cualquier caso no será anterior en esta zona al s. VII a.C.

2.2. El mundo ibérico del sury sureste peninsular. A partir del s. V a.C. la progresiva expansión de la sociedad ibérica unida al proceso de urbanización hace que la residencia de los jerarcas y los lugares de culto se sitúen en lugares diferentes, siguiendo un proceso que ha sido bien definido en Italia por Torelli (1996: 173) y en la Península por Ruiz y Molinos (1993: 265). A partir de este momento, el modelo que podríamos 
intuir para el sacerdocio ibérico debe integrar un complejo sistema en el que al sustrato local hay que añadir una configuración propia en cierta medida próxima al mundo griego e itálico, en donde existe a la vez un personal especializado y una ejecución del ritual reservada al responsable político. Se van a desarrollar además nuevas fórmulas de ocupación territorial y de relación entre comunidades que a menudo se desarrollarán en un marco religioso manifestado a través de santuarios de tipo rural o de colonización.

La presencia de un sacerdocio debe ser un elemento importante en este contexto, y básico para permitir la autonomía del templo, que se erige como uno de los bastiones de la vida ciudadana. Los sacerdotes, como en otros contextos, garantizan una correcta relación entre hombres y dioses mediante el diseño y la ejecución del ritual, lo que no sólo está en relación con las decisiones de carácter político o militar, sino con el desarrollo de todo el ciclo anual de festividades y conmemoraciones que domina la vida agrícola. Por otra parte, la ideología religiosa se diseñará como apoyo al modelo social que se quiere promover, y facilitará la cohesión de la sociedad y el apoyo a las clases dirigentes, en una etapa en que se está promoviendo una organización étnica a través de grupos gentilicios (Almagro Gorbea 1996: 129). Finalmente, el templo supone un centro económico de primera magnitud con recursos nada desdeñables, lo que tendría el valor de la acumulación económica, pero también el de gestión de una de las actividades más promovidas por los jefes ibéricos: el comercio. Los templos, como lugares neutrales y protegidos por la divinidad, eran idóneos para las transacciones comerciales, y así actuaron en el resto del Mediterráneo. Por todo ello, la propia naturaleza y el funcionamiento de la sociedad ibérica parecen precisar de la existencia de un sacerdocio con un importante papel ideológico, político, social y económico.

La existencia de divinidades masculinas, así como femeninas, es un elemento asumido, aunque mal documentado. Sin embargo, la presencia tanto en época orientalizante como tardía de iconografía con alusiones a seres de carácter divino, hace pensar que en el mundo ibérico, como en otros ambientes, se veneraron divinidades de carácter diverso. Una de las más importantes y de más profunda tradición parece ser precisamente la diosa relacionada con la tierra y la fecundidad, que se relacionará en gran medida con Astarté/Tanit (Marín Ceballos 1987). Es más que probable que, como sucede en Grecia, o en el ámbito fenicio-púnico, en el culto a esta diosa las mujeres tuvieran un importante papel como sacerdotisas. Se plantea, por lo tanto, la existencia de un sacerdocio femenino a la vez que el masculino, ligado quizás a lugares de culto específicos.

Ahora bien, ¿Qué elementos podrían ser indicativos de un rango sacerdotal?. Según los modelos de la propia sociedad ibérica y los paralelos mediterráneos, podrían tenerse en cuenta diversos rasgos no excluyentes. a) Un alto nivel social, que mantiene las responsabilidades sacerdotales dentro de las familias principales (Aranegui 1994: 133); b) Objetos implicados en las prácticas rituales ligadas al culto; c) Iconografía específica en lo relativo al aspecto corporal, la vestimenta y asociación a ciertos atributos divinos; d) Posible ausencia de armamento.

a) El primero de los rasgos por sí mismo difícilmente puede ser indicio de la presencia del sacerdocio, ya que será compartido por los niveles más altos de la pirámide social. Sin embargo, será un elemento relevante unido al resto de los caracteres, a los que se sumará como rasgo añadido.

b) En cuanto al segundo, podemos detectar ciertos objetos ligados a la celebración del ritual. Entre ellos, algunos de los más significativos vuelven a ser los cuchillos sacrificiales, aunque tampoco en este caso la evidencia es inequívoca. Como señala Quesada, el cuchillo curvo que acompañaba muchas tumbas aristocráticas de la época orientalizante, desaparecerá en época ibérica en favor de la falcata, a la que se le propone una simbología ritual implícita (Quesada 1997: 167). Una evidencia de este proceso de transición propio de las etapas antiguas de la Cultura Ibérica puede ser el de la estela de Altea la Vella (Morote 1981). Esta pieza, en piedra caliza, presenta una figura humana muy esquemática asociada a una espada de antenas 
y a un cuchillo afalcatado. Los objetos que forman el contexto arqueológico son urnas de orejetas, materiales áticos y un par de broches de cinturón que apuntan a una cronología de fines del s. VI o inicios del s. V a.C. Esta pieza forma parte de una manifestación aún mal conocida, pero relativamente generalizada en el mundo ibérico, que es la de las estelas funerarias (Lucas et al. 1991; Arasa e Izquierdo e.p.). Ciertamente, el cuchillo para el degüello sacrificial se empleó en el mundo ibérico, aunque apenas tenemos muestras iconográficas de ello. Es el caso del bronce representando un personaje masculino que, introducido en una fuente de agua, mata a un carnero (lám. I. 1). La compleja simbología de este personaje ha sido analizada por Olmos (1992: 117), y nos remite a las creencias acerca de la protección que la divinidad ejerce sobre las fuentes de agua y su dominio sobre potenciales peligros, como el de los carnívoros.

Otros cuchillos sacrificiales proceden de contextos de santuario, lo que refuerza su carácter ritual. Es el caso de algunas piezas encontradas en la Encarnación de Caravaca, La Luz en Murcia y Casas Viejas en Almaciles (Granada), que fueron estudiadas por Lillo (1986-7). El tipo I distinguido por este autor tiene una morfología y unas dimensiones propias de este tipo de piezas, por lo que probablemente se trata de cuchillos de sacrificar, utilizados o depositados en los santuarios (Quesada 1997: 164). Otras piezas, de tamaño mucho menor, pudieran ser exvotos, como propone el autor del trabajo. En todo caso nos están indicando la importancia de los rituales de sacrificio, que se llevarían a cabo en estos lugares sagrados y que tienen gran importancia en el devenir de la vida religiosa, así como en el comportamiento económico relacionado con el consumo de carne.

Sin embargo, no todos los sacrificios de este tipo debieron ser practicados por sacerdotes, sino que probablemente se realizarían también prácticas de carácter doméstico con este fin, en las que el sacrificante sería el Pater familias, que adquiriría funciones sacerdotales en ámbitos externos a los recintos sagrados. La práctica de la ofrenda de animales en los ambientes domésticos ha sido reseñada para el mundo catalán (Barrial 1990), y debió practicarse, de una u otra manera, en amplias áreas geográficas. Esta capacidad de los responsables familiares para el ejercicio de cultos privados es algo muy extendido en todo el Mediterráneo, e incluso en los santuarios se podía solicitar que fuera el propio devoto el que sacrificara al animal que ofrendaba, lo que abarataba considerablemente el precio del sacrificio (Ribichini 1988: 120). Todos estos hechos parecen indicar que, aun cuando el cuchillo curvo tiene un importante papel religioso, su uso no es propio sólo de los sacerdotes, por lo que su mera presencia no asegura su asociación a una persona ligada exclusivamente al culto.

Otros muchos objetos bien conocidos están ligados a actividades religiosas. Entre ellos, quemaperfumes, jarros, recipientes de libación, etc., que aparecerán ahora más raramente vinculados a las sepulturas que en época orientalizante, precisamente por el hecho de que los templos y santuarios han adquirido en esta etapa vida propia y son el destino final de todos esos objetos. Conocemos mal el contexto de los santuarios, escasamente excavados y siempre en deficiente estado de conservación, por lo que no se puede por el momento más que suponer su carácter de "tesoros", como sucede en otras áreas, conteniendo tanto ofrendas valiosas como objetos de culto dedicados a la divinidad.

c) En lo referente a iconografía, es bien conocida la existencia de la tonsura, representada en figuras ibéricas, tanto femeninas como masculinas. Cabré (1922) realizó el primer trabajo monográfico sobre este tema, reconociendo algunos personajes tonsurados entre los exvotos de Despeñaperros (fig. 1, $\mathrm{n}^{\circ} 2$ ). Nicolini (1969: 65) aceptará su consideración como sacerdotes, añadiendo a la tonsura otras formas de representación, como la cabeza velada o la cinta ciñendo los cabellos. Considera asimismo, como elementos significativos, la presencia de ricos collares y el hecho de que porten un manto oblicuo con volantes. De la misma opinión es L. Prados (1996: 276), quien señala además el hecho de que estas figurillas no están nunca en actitud oferente, sino que dejan caer los brazos a lo largo del cuerpo. Aceptando que ciertos devotos puedan realizar sacrificios, es asumible que adoptaran también ciertos hábitos formales, como cubrirse la cabeza con el 
manto -aunque el personaje sacrificando un carnero antes citado va descubierto-. Sin embargo, parece muy posible que en ambientes de santuario sólo los sacerdotes y sacerdotisas se representen en esta actitud. En el caso de la tonsura, parece que es innegable un carácter religioso, aunque pudiera tratarse igualmente de un rasgo vinculado a la vejez. En todo caso, los personajes tonsurados del Collado de los Jardines presentan varias características que se juzgan típicas de una posición sacerdotal, como rasgos físicos indicativos, alusión a ricas vestimentas y ausencia de cualquier relación con el armamento.

Estos exvotos tienen además unas características especiales en cuanto a su vestido, consistente en una túnica muy pegada al cuerpo que forma pliegues, en ocasiones dirigidos hacia el eje central de la pieza. Estos rasgos nos permiten enlazarlos con otras imágenes, esta vez en piedra, de marcado carácter ritual. Se trata de las esculturas del conjunto de Porcuna que ya fueron definidas como "sacerdotes" y "sacerdotisas" por González Navarrete (1987: $\mathrm{n}^{\circ} 15$ a 17), y que según Negueruela (1990: 235-242 y 288) formarían un grupo específico junto a una figura sedente de la que sólo quedan los pies y el borde inferior del manto. Todas ellas participan en un acto religioso y el varón, adornado con un brazalete y un colgante, porta un manípulo y seguramente está a punto de realizar un sacrificio (Blanco 1988: 4). Parece tratarse de un caso claro de práctica sacerdotal, si bien ignoramos una vez más si se trataba de un ejercicio permanente o del cumplimiento de una acción puntual por parte de un personaje revestido de autoridad política. Es de señalar que, a lo largo del tiempo, las vestiduras más delicadas, es decir, las túnicas de lino que se ajustan al cuerpo, son un elemento que se repetirá en las personas vinculadas a acciones rituales. Un ejemplo que nos remite a otro estilo, otro contexto y otra cronología, es el del pilar-estela de las "damitas" de Corral de Saus (Mogente, Valencia) (Fletcher y Pla 1977; Izquierdo 1995), en el que cuatro jóvenes portan frutos en sus manos y van vestidas con una túnica por debajo de la rodilla, ceñida con cinturón. Sus cabezas están descubiertas, y su peinado de trenzas con amplios bucles tiene sus paralelos no sólo en la zona del sureste (Cuadrado 1984: 287), sino también entre los exvotos de los santuarios de Jaén (Nicolini 1969: lám. XXI: 1-4).

Pero volviendo a la tonsura, ésta no es exclusiva de los exvotos de bronce. También aparece ocasionalmente en algunas figuras de piedra. Una representación bien conocida es la de la pequeña estela de La Albufereta, de contexto funerario y cuyo personaje, contra lo que sucede en los pequeños bronces de Despeñaperros, está armado al menos con una lanza (Llobregat 1972: lám. VII). Su vestimenta indica su relevancia social, ya que no sólo lleva ricos ropajes, sino algunos signos de rango que pudieran también tener un sentido religioso, como ha señalado Aranegui (e.p.). Entre ellos figuran los pendientes amorcillados y las cintas cruzadas sobre el cuello, algo muy extendido en la iconografía de los personajes principales y de los actos de connotación ritual (además de los casos citados por Aranegui pueden reseñarse los del personaje principal de El Pajarillo (Molinos et al. e.p.) o el del busto de varón procedente de Baza (Chapa y Olmos 1997). Se relaciona así la condición aristocrática con la práctica religiosa, haciéndose más probable que ciertos personajes públicos tuvieran su lugar en la práctica del culto, relacionándose en cierta medida con lo sobrenatural, aspecto fundamental en la ideología que sustentaba las élites.

Podemos analizar brevemente otros dos ejemplos relacionados con la escultura en piedra: el cipo de Jumilla y las esculturas del Cerro de los Santos. En el primer caso, mucho se ha especulado con el significado de las figuras, tanto con los que parecen protagonistas del relato como con los jinetes que circundan la escena principal (bibliografía recogida en García Cano 1997: 263-270). Uno de estos jinetes sujeta un báculo con lo que parece una posición ritualizada de la mano, y además lleva tonsurada la parte delantera de la cabeza, cubierta a su vez con una tela. Quizás podríamos tener aquí la imagen de un sacerdote, que con las patas de su caballo domina tanto el mundo animal como el humano. En cuanto a las representaciones del Cerro de los Santos, poco puede añadirse a lo ya presentado por Ruiz Bremon (1989), y con más detalle por Ruano (1987). Esta última autora propone el reconocimiento de figuras sacerdotales en diversos yacimientos, y resalta la tonsura como indicio sacerdotal en algunas figuras del Cerro (Ruano 1987: esculturas AB 181 y 187, entre otras). 
Un elemento clave en este yacimiento albacetense es la abundante presencia de representaciones femeninas, tanto estantes como sedentes. Todas ellas van veladas, y mientras que algunas portan ofrendas, la mayor parte de las mujeres sentadas adoptan una actitud hierática, con las manos sobre las rodillas. Ésta postura sedente ante la presencia divina no es característica de devotas que van a solicitar favores, sino que más bien se acerca a lo que sería la representación de la propia diosa en su trono. Puede sugerirse, en este caso, que nos encontremos en un santuario dedicado por lo menos a una divinidad femenina, en el que la presencia de sacerdotisas adquiriría una gran importancia. Estas podrían asimilarse a la figura de la diosa, o vincularse directamente con su iconografía, como sus representantes. La vinculación con el culto estaría además ligada a las clases sociales más altas, algunas de cuyas jóvenes se dedicarían algún tiempo al servicio del templo, como fue propuesto por Griñó (1992: 203) o por Ruano (1987), correspondiendo a ellas algunas de las esculturas estantes. Esto podría tener una larga tradición que en esta zona se constataría a través del timiaterio de La Quéjola, en el que se representa a una joven adolescente portando una paloma, símbolo de la diosa (Blánquez y Olmos 1993). La divinidad femenina no excluiría otra masculina, o la dedicación de los hombres al culto como un cuerpo con funciones sacerdotales, lo que podría deducirse a su vez de muchas de las esculturas allí recuperadas. Por su parte, las esculturas sedentes, tanto masculinas como femeninas, procedentes de otros yacimientos, como el Llano de la Consolación o Cabecico del Tesoro, debieron estar también estrechamente ligadas a esta significación religiosa.

Esta lectura puede extenderse a la Dama de Baza, que incluye en las entrañas del trono de la diosa los restos de un personaje, quizás femenino (Reverte 1986), enterrado con un complejo ritual. La figura encierra en su mano izquierda un pichón, lo que nos lleva a considerar otro elemento que nos aproxima al mundo de los dioses, a través de sus atributos. La paloma es un símbolo que surge una y otra vez tanto en contextos domésticos como religiosos y funerarios, asociada no sólo a la escultura monumental, sino a bronces (fig. 1.3), terracotas (fig. 1.1), joyas y cerámicas (fig. 1.4), en lo que parece una alusión a la diosa femenina más extendida en ambientes de influjo púnico: Tanit (J. Pereira Sieso, com.per.). Parece que en el mundo ibérico, como en otros ambientes mediterráneos, la paloma tuvo un papel importante en el ritual, y su vinculación con la divinidad hace que sus representaciones puedan relacionarse con personas ligadas al culto, si bien podrían ser también signos de ofrenda, a la vez que de protección de la diosa.

La información iconográfica ofrecida por la cerámica en sus expresiones figurativas tiene un potencial enorme (Aranegui 1997; Tortosa 1996) que no puede tratarse aquí en extenso. Sin embargo, merece la pena citar un interesante trabajo de C. Aranegui (1995), en el que se destaca la presencia de arúspices en los cultos ibéricos, ejemplificados en la iconografía de ciertas cerámicas de S. Miquel de Lliria. La vestimenta de estas figuras, con la cabeza encapuchada y las tiras cruzadas sobre el pecho, revelarían su condición especial y el hecho de estar practicando una ceremonia que requiere estos atuendos. La asociación además de uno de ellos con una paloma reforzaría su carácter religioso.

d) Nos queda otro rasgo de los escogidos para significar un carácter sacerdotal, que debiera ir unido en gran medida a los anteriores, y que es más significativo de los sacerdocios masculinos. Se trata de ausencia de armas, que en muchas religiones del entorno mediterráneo era preceptiva, salvo circunstancias excepcionales. Voy a proponer aquí, a falta de registros más numerosos, el carácter eminentemente religioso de ciertos enterramientos de la Alta Andalucía que parecen implicar una comunidad religiosa con ritos y creencias comunes en la Bastetania andaluza. Los ejemplos propuestos corresponden a tres de las principales necrópolis de la zona: Castellones de Céal, Galera y Baza, y tienen características diversas, pero también elementos comunes que pasamos a analizar.

En Castellones de Céal la tumba 11/145 (Chapa et al. 1991) es morfológicamente una fosa cuadrada de $2 \mathrm{~m}$ de profundidad, dividida en dos pisos. El interior, forrado con tablones de madera y con el suelo de adobe, incluye 4 vasos de borde exvasado, uno de los cuales sirvió de urna cineraria, siendo el único 
que poseía tapadera (lám. I.2). Los demás, aparentemente vacíos, se situaban en las esquinas del recinto funerario. Aunque estaban pintados, unas virutas de yeso que los rodeaban mostraban claramente que en origen habían recibido un baño de este material, y probablemente se repintaron sobre este soporte, como sucedió en Baza. La iconografía vegetal polícroma que suele formar parte de estas decoraciones también está en relación con las manifestaciones divinas, pero aquí no se ha conservado.

Los restos quemados inhumados en la urna correspondían a un varón de unos 50 años de edad, que portaba dos pendientes amorcillados, unas pinzas de depilar, un gran botón con esvástica, una sencilla cuenta de piedra y un gran anillo de plata, todo lo cual fue incluido junto con los huesos. Acompañando a los tres vasos restantes se encontraba una copa ática de figuras rojas con representación de un joven ante un altar. Este piso se techaba nuevamente con tablones de madera, sobre los que fue depositado un conjunto de cuatro platos de cerámica negra y un pequeño vasito tintero del mismo color, junto con cáscaras de huevo de gallina. La tumba, fechada muy a principios del s. IV a.C., corresponde aproximadamente con el momento de refundación del poblado, y nos presenta a un hombre de alto rango social con un esquema de deposición del ajuar muy ritualizado -vasos en las esquinas, ofrendas en el piso superior, etc.-. Es de suponer que en estos momentos iniciales de la vida del poblado, la propia elección del emplazamiento, la definición de la necrópolis como espacio sagrado, etc., implicara la presencia de individuos con reconocida autoridad religiosa, y uno de ellos podría bien ser el correspondiente a esta sepultura.

En la necrópolis de Galera haremos alusión a una tumba muy conocida a través de la bibliografía, que recibió el número 20 en el catálogo elaborado por Cabré y Motos (1920). La tumba era de mampostería, con corredor de acceso, pero se había perdido cuando llegaron los dos investigadores. Respecto al ajuar (lám. II.1), la descripción ofrecida por los autores de los trabajos habla por sí misma: "El ajuar se componía de: cuatro vasijas gemelas... de tamaño distinto, las cuales primeramente hemos de decir que fueron repintadas, tal vez en el acto del sepelio, de un rojo uniforme; y en segundo término, que se cubrían esos recipientes por platos, siendo singular el de la urna mayor, que termina con una granada, la cual se modeló con el mismo barro de la tapadera, y el de la más pequeña es notable por lo aplanado de su forma... Además constaba de otros dos platos, que todavía conservan restos de una especie de enyesado artificial, debajo del que, por dentro y por fuera de ambos, vense unos grabados muy irregulares de líneas onduladas...; también un kylix, dos anforitas de pasta vítrea con labores de matices distintos, verde y amarillo sobre azul oscuro: una palmeta de bronce, terminación acaso del asa de un oenochoe, de estilo griego, y la escultura de diosa femenina..." (Cabré y Motos 1920: 26).

Esta sepultura es claramente más importante que la de Céal y anterior a ella en el tiempo-segunda mitad del s. V a.C.-, pero básicamente sus elementos son los mismos. Es de suponer que el vaso mayor fuera la urna cineraria, y quizás junto a los huesos se incluirían otros elementos personales que no han llegado hasta nosotros. Uno de los objetos más relevantes del conjunto es una palmeta, inicialmente relacionada con un jarro de bronce, pero que después fue reconocida como perteneciente a una pátera griega, e interpretada como un regalo que el aristócrata ibérico recibiría de sus contactos mediterráneos. Estos, además, remiten a un mundo colonial oriental, ya que la mayor parte de los paralelos ofrecidos proceden del Norte de Grecia o del área del Mar Negro (Shefton 1991: 309). Por otro lado, la existencia de un jarro o la alusión a él, se relaciona con ritos de libación. La pieza más claramente vinculada a un culto vinculado con una divinidad femenina es, sin embargo, la famosa escultura en alabastro conocida como "Dama de Galera", que aunque de una cronología muy anterior, acompañó al difunto/a (?) a la sepultura. No hay alusión alguna a la presencia de armas. Esta sepultura refuerza claramente los aspectos rituales, y también podría ser indicativa de alguna persona directamente relacionada con el culto, como ya apuntó en su día Olmos (1991:301). Es de señalar que, con una diferencia temporal notable, esta sepultura incorpora todos los elementos que van a caracterizar a la tumba más famosa de esta zona, y que pasamos a analizar. 
Se trata, naturalmente, de la t. 155 de Baza, que incluía la famosa Dama (Presedo 1982). De nuevo contamos aquí con los recipientes rituales de esquina, y los vasos acampanados recubiertos de yeso y pintados con motivos florales (lám. II.2). La escultura de piedra no ofrece dudas respecto a su relación con una divinidad femenina. Si la atribución osteológica hecha por Reverte (1986) fuera correcta, podríamos estar ante una persona directamente relacionada con el servicio a la diosa, e incluso ante su representante en un posible templo o santuario vinculado a la ciudad. Ciertamente, en este enterramiento son numerosos los elementos correspondientes a armamento, pero como ya se ha señalado, no constituyen un ajuar convencional de guerrero, sino que parecen una serie de ofrendas arrojadas a los pies de la diosa, fruto de los rituales fúnebres y correspondientes quizá a distintos jefes de grupos gentilicios (Quesada 1997: 637).

Estas tumbas no son las únicas que existen en estas necrópolis con los mismos rasgos, y una revisión detallada podría revelarnos más casos similares. Es llamativo, en todo caso, que los ajuares y la forma de las tumbas presenten, no ya una identidad, pero sí unas similitudes tan importantes en casos que se escalonan a lo largo de casi un siglo. Quedan muchas posibilidades por desarrollar. Una de ellas se centraría en la conexión de las representaciones figurativas con este contexto específicamente religioso. Los vasos, que previamente han recibido una decoración geométrica convencional, se cubren de yeso y se repintan con motivos florales, y en ocasiones con temas zoomorfos. La presencia de las alusiones a la granada de nuevo nos integran en un mundo vegetal ligado a las divinidades del más allá. Parece que, en cierta medida, estamos ante los precedentes de lo que será la eclosión posterior de los temas vegetales de carácter simbólico que caracterizarán las cerámicas de Elche (Tortosa 1997).

Precisamente con la entrada en la etapa final de la Cultura Ibérica se desarrollará con más fuerza el fenómeno religioso, y tanto los santuarios como los templos de diversas características y advocaciones van a proliferar en casi toda la geografía del oriente peninsular (Lillo 1993-4). En estos momentos es de suponer que el ejercicio del sacerdocio se va a generalizar, si bien desconocemos, como ocurría hasta ahora, cuál es la configuración de este clero, que al sustrato local añadirá un fuerte influjo de carácter púnico relacionado con la presencia cartaginesa, a la que se añade la creciente presencia romana (Almagro-Gorbea 1996: 132).

En definitiva, de todo lo expuesto se pueden recoger una serie de puntos que, más que conclusiones, son propuestas abiertas a la discusión y a su futuro análisis a través de la evidencia arqueológica. Estas pueden resumirse así:

— En época ibérica debió existir un clero, más organizado cuando, a lo largo del s. V y en relación con el proceso de urbanización progresiva, las estructuras de culto se van segregando de los palacios. Este fenómeno va ligado al desarrollo político y económico de la sociedad, encauzado hacia una creciente definición étnica y una complejidad social cada vez mayor. Esto posibilitará la proliferación de templos y santuarios a partir del s. III a.C., dentro de la creciente órbita cartaginesa y romana.

- El clero debió pertenecer a la clase dirigente, y aunque desconocemos su configuración, pudo ejercer un poder notable en su entorno social. En las ceremonias más importantes del ritual público los oficiantes pudieron ser los mismos jefes políticos, pero probablemente existió un cuerpo sacerdotal específico, que contaría tanto con hombres como con mujeres, ligados a las divinidades masculinas y femeninas.

- El clero se diferenciaría y jerarquizaría conforme a los tipos de santuario. Dentro de los rurales, la riqueza iría unida a la popularidad y efectividad de la divinidad. Estos santuarios cumplirían un importante papel aglutinante, y estarían dedicados a divinidades de carácter "práctico", útiles a todos, por lo que servirían de válvula capilar de relación entre diversos grupos y etnias. Se mantendría en ellos un clero constante y especializado. Por su parte, los templos urbanos protegerían a un grupo más restringido, y la divinidad tendría relación 'con el núcleo dirigente. Los sacerdotes procederían de las familias aristocráticas. Existe la posibilidad de que algunas de ellas lo ejercieran con carácter hereditario.

- En niveles más reducidos, el carácter religioso estaría presente en los pequeños asentamientos a través de sus jefes locales, y en el espacio doméstico a través de los cabezas de familia. 


\section{Agradecimientos}

Este trabajo debe mucho a las ideas y comentarios de varias personas, entre las que cabe destacar la ayuda prestada por Ricardo Olmos, Juan Pereira o Isabel Izquierdo.

\section{BIBLIOGRAFÍA}

ALMAGRO-GORBEA, M. (1978): "Los relieves mitológicos orientalizantes de Pozo Moro". Trabajos de Prehistoria. 35: 251-278.

(1996): Ideología y Poder en Tartessos y el Mundo Ibérico. Real Academia de la Historia. Madrid.

ARANEGUI, C. (1994): "Iberia Sacra Loca. Entre el Cabo de la Nao, Cartagena y. el Cerro de los Santos". Revista de Estudios Ibéricos. 1: 115-138.

(1995): "Los Iberos y los auspicios. A propósito de un vaso decorado de la antigua Edeta (Lliria, Valencia)". En de Miguel Zabala, A. J., F. E. Álvarez Solano y J. San Bernardino Coronil (eds): Arqueólogos, Historiadores y Filólogos. Homenaje a Fernando Gascó. 2 vols. Vol. 1. Kolaios 4: 39-51. Sevilla.

— (ed) (1997): Damas y caballeros en la ciudad ibérica. Ed. Cátedra. Madrid.

- (e.p). "Signos de rango en la sociedad ibérica. Distintivos de carácter civil o religioso". Revista de Estudios Ibéricos. 2.

ARASA, F.; IZQUIERDO, I. (e.p.): "Estelas antropomorfas con inscripción ibérica de Mas de Barberá (Nogueruelas, Teruel)". Archivo Español de Arqueología.

ARRIBAS, A. (1976): Los Iberos. Ed. Aymà. Barcelona.

AUBET, M. E. (1994): Tiro y las Colonias Fenicias de Occidente. Crítica, Barcelona.

BARRIAL I, O. (1990): "El ritual del sacrificio en el mundo ibérico catalán”. Zephyrus. XLIII: 243-248.

BELÉN, M.; ESCACENA, J. L. (e.p): "Testimonios religiosos de la presencia fenicia en Andalucía occidental". Revista del Centro de Estudios del Próximo Oriente.

BIETTI SESTIERI, A. M. (1992): The Iron Age Community of Osteria dell'Osa. Cambridge University Press.

BLANCO, A. (1987/1988): "Las esculturas de Porcuna. I. Estatuas de guerreros; II. Hierofantes y cazadores; III. Animalia". Boletín de la Real Academia de la Historia. CLXXXIV: 405-445; CLXXXV: 1-27 y 206-234.

BLÁNQUEZ, J. (1997): "Caballeros y aristócratas del s. V a.C. en el mundo ibérico". En R. Olmos y J.A. Santos (eds): Iconografía Ibérica, Iconografía Itálica. Propuestas de interpretación y lectura. Serie Varia 3. Universidad Autónoma de Madrid. 211-234.

BLÁZQUEZ, J. M. (1983): Primitivas religiones ibéricas. t. II. Religiones prerromanas. Ed. Cristiandad. Madrid.

BOUMET, C.; XELLA, P. (1995): “La Religion”. V. Krings (ed): La Civilisation Phénicienne et Punique. Manuel de Recherche. E.J. Brill. Leiden. 316-333.

CABRÉ, J.; MOTOS, F. (1920): "La necrópolis ibérica de Tútugi, Galera Provincia de Granada". Junta Superior de Excavaciones y Antigüedades. Memoria $\mathbf{n}^{\circ} 21$ (1918), Madrid.

CABRÉ, J. (1922): "La Tonsura Ibérica". Actas y Memorias de la Sociedad Española de Antropología, Etnografía y Prehistoria. Año I, t. I: 163-170.

CELESTINO, S. (1995). "Los santuarios tartéssicos y su influencia en la Cultura Ibérica". J. Blánquez (ed): ElMundo Ibérico: una nueva imagen en los albores del año 2000. Col Imágenes y Palabras. Junta de Comunidades de Castilla-La Mancha. Toledo.

CHAPA, T.; PEREIRA, J.; MADRIGAL, A.; LÓPEZ, M. T. (1991): "La sepultura 11/145 de la necrópolis ibérica de Los Castellones de Ceal (Hinojares, Jaén)". Trabajos de Prehistoria. 48: 333-340. 
CHAPA, T.; OLMOS, R. (1997): "Busto de varón hallado en Baza". Olmos, R. y Tortosa, T. (eds): La Dama de Elche. Lecturas desde la diversidad. Colección Lynx. Agepasa. Madrid. 163-170.

COLDSTREAM, J. N. (1985): “Greek Temples: why and where?”. En Easterling, P.E. y Muir, J.V. (eds): Greek Religion and Society. Cambridge University Press. 67-97.

CUADRADO, E. (1984): "Restos monumentales funerarios de El Cigarralejo". Trabajos de Prehistoria 41: 251-290.

CUNLIFFE, B. W. et al. (1993): "Torreparedones, poblado fortificado en altura, y su contexto en la Campiña de Córdoba". Investigaciones Arqueológicas en Andalucía 1985-1992. Proyectos. Junta de Andalucía. Huelva: 519-528.

DELATTRE, H. (1898): Carthague. Nécropole Punique voisine de Sainte-Monique. Deuxième Semestre des Fouilles. Separata de Cosmos. Paris.

DICTIONNAIRE (1992): ...de la Civilisation Phenicienne et Punique”. Ed. Brepols.

EASTERLING, P. E. (1985): "Greek poetry and Greek religion". En Easterling, P.E. y Muir, J.V. (eds): Greek Religion and Society. Cambridge University Press. 34-48.

FINLEY, M. (1985): "Foreword". En Easterling, P.E. y Muir, J.V. (eds): Greek Religion and Society. Cambridge University Press. I-XXII.

FLETCHER, D.; PLA, E. (1977): "Restos escultóricos de la necrópolis ibérica de Corral de Saus (Mogente, Valencia)". Homenaje a García Bellido. Revista de la Universidad Complutense. XXVI, 109, vol. III: 56-62.

GARCÍA CANO, J. M. (1997): Las necrópolis ibéricas de Coimbra del Barranco Ancho (Jumilla, Murcia) I. Las excavaciones y estudio analítico de los materiales. Universidad de Murcia.

GARRIDO, J. P.; ORTA, E. (1978): Excavaciones en la Necrópolis de La Joya. Huelva. II. Excavaciones Arqueológicas en España 96. Ministerio de Cultura. Madrid.

GONZÁLEZ NAVARRETE, J. (198): Escultura Ibérica de Cerrillo Blanco, Porcuna, Jaén. Diputación Provincial de Jaén. Instituto de Cultura. Jaén.

GOULD, J. (1985) "On making sense of Greek Religion”. Easterling, P.E. y Muir, J.V. (eds): Greek Religion and Society. Cambridge University Press: 1-32.

GREEN, M. A. (1993): "La religión celta". Almagro Gorbea, M. y Ruiz Zapatero, G. (eds): Los Celtas: Hispania y Europa. Universidad Complutense. Madrid. 451-475.

GRIÑO, B. (1992) "Imagen de la mujer en el mundo ibérico. La Sociedad Ibérica a través de la imagen". Ministerio de Cultura. Madrid. 194-205.

IZQUIERDO, M. I. (1995): "El contexto arqueológico de las dos grandes tumbas del Corral de Saus (Moixent, Valencia)". Verdolay. 7: 217-238.

KRON, U. (1996): "Priesthoods, Dedications and Euergetism. What Part did Religion Play in the Political and Social Status of Greek Women?". En Hellström, P. y Alroth, B. (eds): Religion and Power in the Ancient Greek World. Boreas 24. Acta Universitatis Upsaliensis. Uppsala. 139-181.

LILLO, P. (1986-7): "Un singular tipo de exvoto: las pequeñas falcatas". Cuadernos de Prehistoria y Arqueología. Universidad Autónoma de Madrid. Homenaje al Profesor Gratiniano Nieto. vol II: 33-46.

_- (1993-1994): "Notas sobre el templo del Santuario de La Luz (Murcia)". Anales de Prehistoria y Arqueología. 9-10: 155-173. Universidad de Murcia.

LLOBREGAT, E. (1972): Contestania Ibérica. Instituto de Estudios Alicantinos. Alicante.

LUCAS, R.; RUANO, E.; SERRANO, J.L. (1991): "Escultura ibérica de Espejo (Córdoba): hipótesis sobre su funcionalidad". Espacio, Tiempo y Forma. Serie II, t. IV: 297-318.

MALKIN, I. (1987): Religion and Colonization in Ancient Greece. E.J. Brill. Leiden.

MARCO, F. (1993): "La religiosidad en la Céltica hispana”. Almagro Gorbea, M. y Ruiz Zapatero, G. (eds): Los Celtas: Hispania y Europa. Universidad Complutense. Madrid. 477-512. 
MARÍN CEBALLOS, M. C. (1987): “¿Tanit en España?”. Lucentum. 6:.

MOLINOS, M. et al. (e.p.) El santuario heroico de El Pajarillo (Huelma, Jaén). Diputación Provincial. Universidad de Jaén.

MUIR, J. V. (1985): "Religion and the new education: the challenge of the Sophists". En Easterling, P.E. y Muir, J.V. (eds): Greek Religion and Society. Cambridge University Press. 191-217.

NEGUERUELA, I. (1990): Los monumentos escultóricos ibéricos del Cerrillo Blanco de Porcuna(Jaén). Ministerio de Cultura. Madrid.

NICOLINI, G. (1969): Les bronzes figurés des sanctuaires ibèriques. Presses Universitaires de France. Paris.

OLMOS, R. (1991): “Apuntes ibéricos. Relaciones entre la élite ibérica y el Mediterráneo en los siglos V y IV a.C.". Trabajos de Prehistoria 48: 299-308.

(1992): "Iconografía y culto a las aguas de época prerromana en los mundos colonial e ibérico". Espacio, Tiempo y Forma. Serie II. Historia Antigua. V: 103-120

PALLOTINO, M. (1975): The Etruscans. Indiana University Press. Bloomington y Londres.

PRADOS, L. (1997): "Los ritos de paso y su reflejo en la toréutica ibérica”. En R. Olmos y J.A. Santos (eds): Iconografía Ibérica, Iconografía Itálica. Propuestas de interpretación y lectura. Serie Varia 3. Universidad Autónoma de Madrid. 273-282.

PRESEDO, F. (1982): La Necrópolis de Baza. Excavaciones Arqueológicas en España 119. Ministerio de Cultura, Madrid.

QUESADA, F. (1997): El armamento ibérico. Estudio tipológico, geográfico funcional, social y simbólico de las armas en la Cultura Ibérica (siglos VI-I a.C.). Monographies Instrumentum 3. 2 vols. Ed. Monique Mergoil. Montagnac.

REVERTE, J. M. (1986): “Informe antropológico y paleopatológico de los restos cremados de la Dama de Baza". Catálogos y Monografías del M.A.N. 10: 187-192.

RIBICHINI, S. (1988): "Creencias y Vida Religiosa". Los Fenicios. Ed. Folio. Madrid. 104-124.

RICHTER, G. M. A. (1968). Korai. Archaic Greek Maidens. Phaidon Press. Londres.

RUANO, E. (1987): La escultura humana de piedra en el mundo ibérico. Madrid. 3 vols.

RUIZ, A.; MOLINOS, M. (1993): Los Iberos. Análisis arqueológico de un proceso histórico. Crítica, Barcelona.

SHEFTON, B.B. (1991): "Comentarios a los apuntes ibéricos". Trabajos de Prehistoria 48: 309-312.

SPIVEY, N. (1996): Understanding Greek Sculpture. Ancient Meanings, Modern Readings. Thames and Hudson. Londres.

SZEMLER, G. J. (1972): The Priests of the Roman Republic. A study of interactions between Priesthoods and Magistracies. Col. Latomus 127. Bruselas.

TORELLI, M. (1996): Historia de los Etruscos. Crítica. Barcelona.

TORELLI, M. (1997): “Reges latini della Preistoria: iconografia, cerimoniale statuti”. Olmos, R. y Santos, J.A. (eds): Iconografía Ibérica, Iconografía Itálica. Propuestas de interpretación y lectura. Serie Varia 3. Universidad Autónoma. Madrid. 21-42.

TORTOSA, T. (1996): "Imagen y símbolo en la cerámica ibérica del Sureste”. En Olmos, R. (ed): Al otro lado del espejo. Aproximación a la imagen ibérica. Col. Lynx. Madrid: 145-162.

TORTOSA, T. (1997): "Los signos vegetales en la cerámica ibérica de la zona alicantina". En R. Olmos y J.A. Santos (eds): "Iconografía Ibérica, Iconografía Itálica. Propuestas de interpretación y lectura". Serie Varia 3. Universidad Autónoma de Madrid. 177-192.

TURCAN, R. (1988): Religion Romaine. Vol. 2. Iconography of Religions. E.J. Brill. Leiden. 

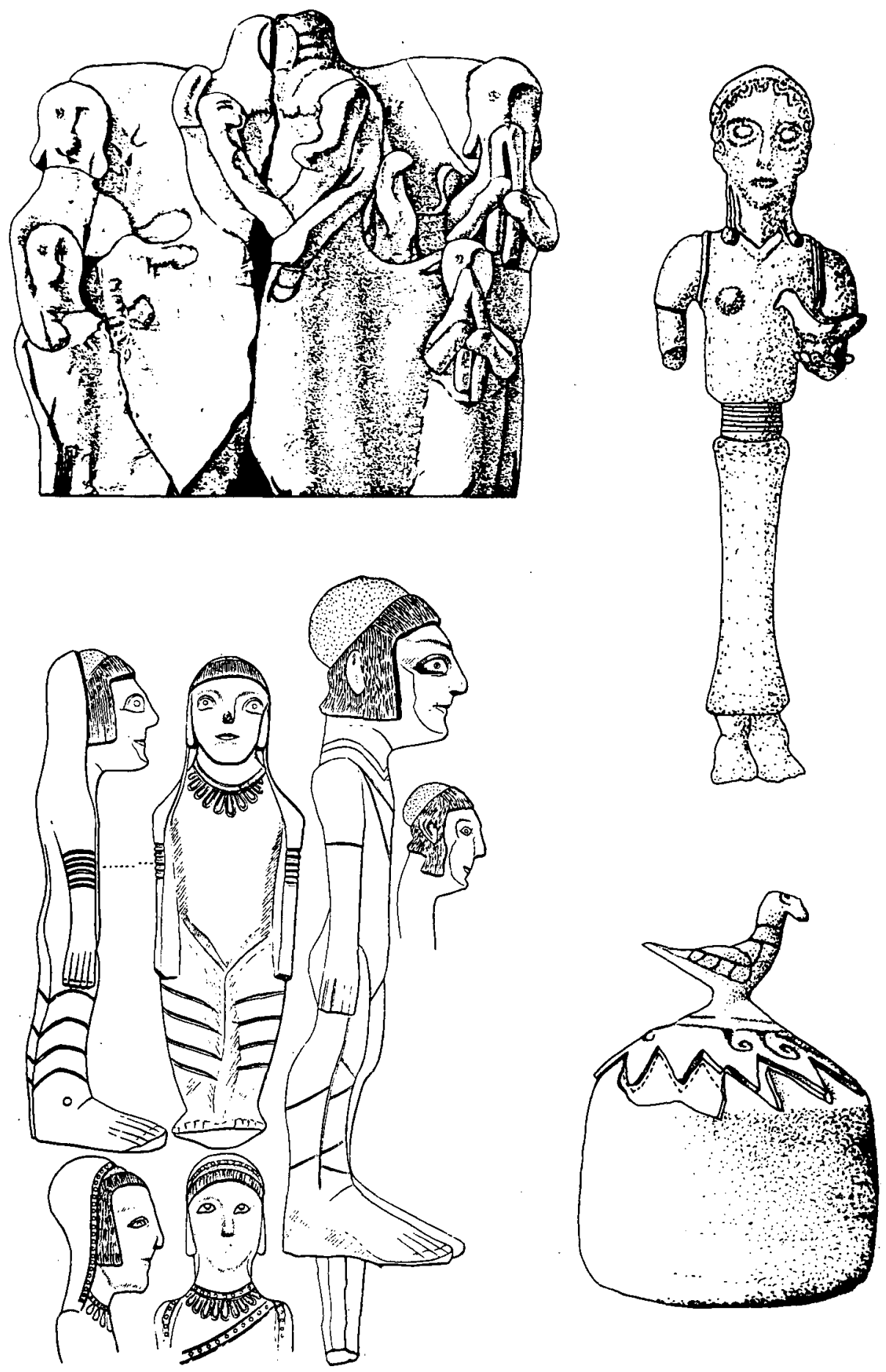

Figura 1: 1.- Terracota de La Serreta de Alcoy. Altura. $16,7 \mathrm{~cm}$.

2.- Bronces representando personajes tonsurados. Santuario del Collado de los Jardines (Jaén). Según J. Cabré. Altura pieza mayor: $7 \mathrm{~cm}$.

3.- Exvoto femenino de bronce portando una paloma. Collado de los Jardines (Jaén). Altura: 13,8 cm. 4.- Cajita de cerámica con asa ornitomorfa. Alcoy. 


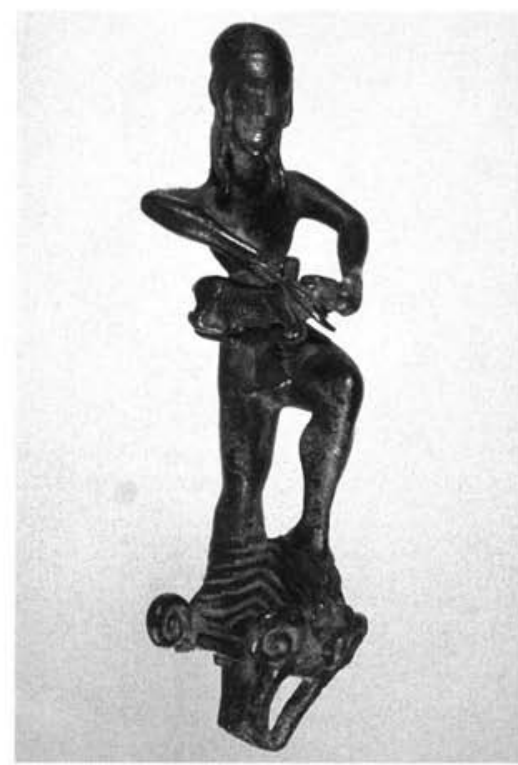

Lámina I: 1.- Personaje sacrificando un carnero. Altura. $15,5 \mathrm{~cm}$. Foto: A. Trigo. Archivo Fotográfico del Museo Arqueológico Nacional.

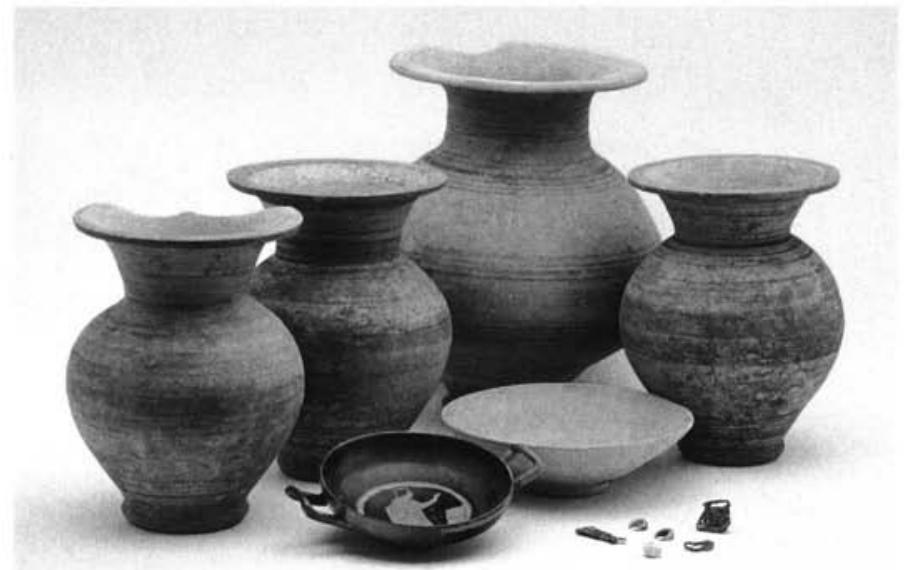

Lámina I: 2.- Castellones de Ceál (Hinojares, Jaén). Ajuar de la tumba 11/145. 


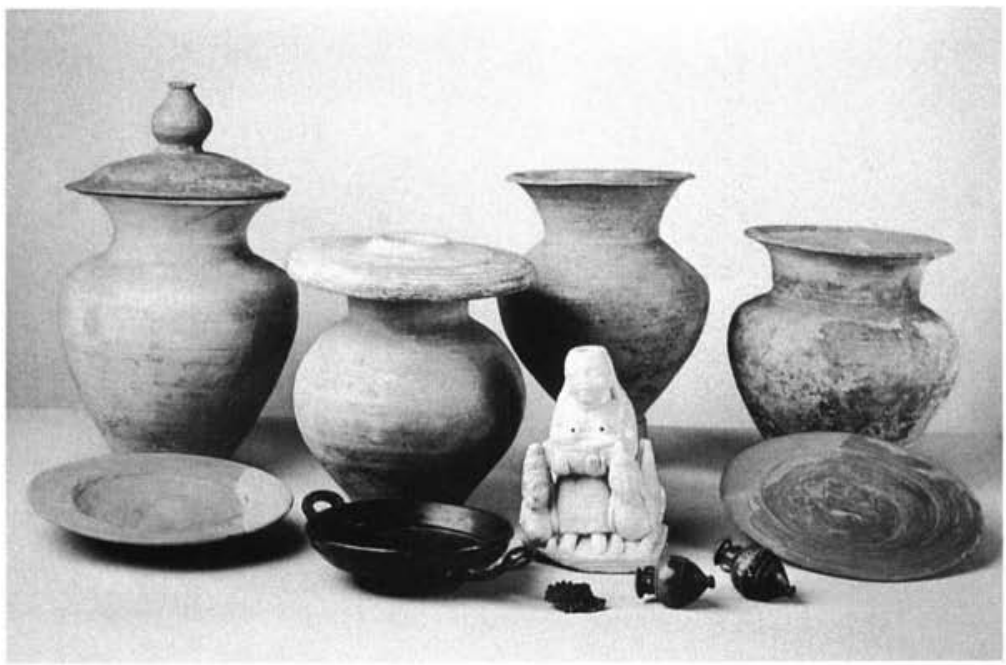

Lámina II: 1.- Galera (Granada), Ajuar de la tumba 20. Foto: E. Sáez. Archivo Fotográfico del Museo Arqueológico Nacional.

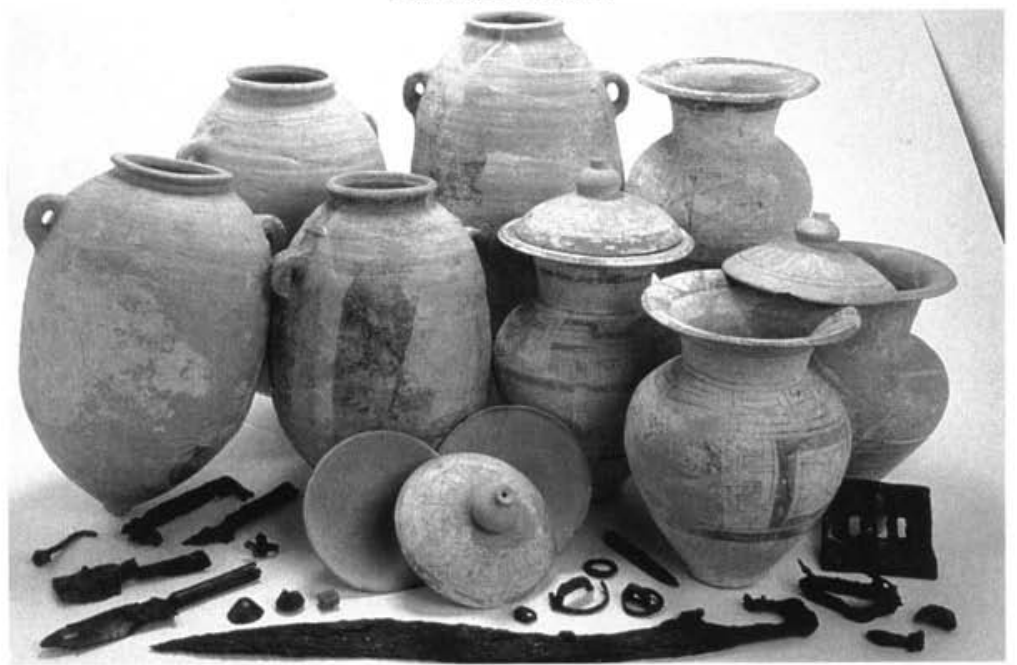

Lámina II: 2.- Baza (Granada). Ajuar de la tumba 155. Foto: Actividades y Servicios Fotográficos. Archivo Fotográfico del Museo Arqueológico Nacional. 